\title{
Analisa Fatigue pada Rangka Sepeda Trandem dengan Menggunakan Metode Elemen Hingga
}

\author{
Arief Maulana, Julendra Bambang Ariatedja \\ Departemen Teknik Mesin, Fakultas Teknologi Industri, Institut Teknologi Sepuluh Nopember \\ e-mail: ariefcanga@gmail.com
}

\begin{abstract}
Abstrak-Sepeda Trandem diciptakan untuk mengakomodir kebutuhan masyarakat akan sepeda solo dan sepeda tandem dalam satu sepeda. Oleh karena itu dibutuhkan penelitianpenelitian selanjutnya untuk melengkapi dan mendukung inovasi tersebut. Penelitian dimulai dengan studi literatur, studi awal, serta pengumpulan data-data dari penelitian sebelumnya yang nantinya akan dijadikan dasaran untuk melakukan permodelan pada perangkat lunak elemen hingga. Dilakukan permodelan dengan menggunakan solid meshing dengan ukuran $5 \mathrm{~mm}$ dan Span Angle Fine, serta pembebanan diakibatkan oleh pengendara dengan massa $100 \mathrm{~kg}$ tanpa memperhatikan kondisi jalan pada pembebanan minimum, dan memperhitungkan kondisi ketika menghadapi speed bump dengan tinggi $\pm 0.2 \mathrm{~m}$ sehingga diberikan koefisien dinamis sebesar 3, data yang akan didapatkan berupa Maximum Stress Principal (Von Mises), yang selanjutnya akan diolah menjadi Fatigue Life dan Fatigue Safety Factor dari sepeda Trandem. Hasil dari penelitian ini didapatkan bahwa terjadi overdesign dari segi fatigue, dikarenakan nilai fatigue life yang terlalu besar, sehingga dilakukan improvement pada rangka sepeda Trandem. Improvement dilakukan dengan mengecilkan ketebalan rangka sepeda Trandem, yang semula memiliki tebal sebesar $3 \mathrm{~mm}$ menjadi $1.5 \mathrm{~mm}$, dan didapatkan penurunan nilai fatigue life yang signifikan menjadi \pm 18 tahun dengan nilai fatigue safety factor $\mathbf{0 . 8 6 2 6}$.
\end{abstract}

Kata Kunci_Analisa Fatigue, Metode Elemen Hingga, Sepeda.

\section{PENDAHULUAN}

I NDUSTRI sepeda di Indonesia merupakan salah satu industri yang maju di Indonesia, selain Cina, Taiwan, dan India [1]. Dan jumlah sepeda yang dipergunakan untuk BikeSharing Program di Asia mencapai angka 367,240 unit sepeda [2] yang membuktikan bahwa sepeda merupakan salah satu alat transportasi yang banyak digunakan.

Hal ini mendorong terciptanya banyak inovasi pada industri sepeda. Salah satu inovasi yang ada di Indonesia adalah sepeda Trandem yang diciptakan oleh bapak Bambang Iskandriawan M. Eng. , dosen Desain Produk ITS. Sepeda Trandem adalah merupakan sepeda yang didesain untuk mengakomodir kebutuhan masyarakat akan sepeda solo dan sepeda tandem dalam satu sepeda. Dan untuk mendukung hal tersebut dibutuhkan analisa terhadap sepeda Trandem ini salah satunya Fatigue Analysis untuk mencari tahu Fatigue Life dan Fatigue Safety Factor dari rangka sepeda akibat dari pembebanan dengan metode elemen hingga (Finite Element Method).

Penggunaan Fatigue Analysis pada penelitian ini dimaksudkan untuk mecari Fatigue Life dan Fatigue Safety
Factor dari rangka sepeda Trandem. Penelitian ini diharapkan dapat menjadi referensi untuk penelitian selanjutnya,

Metode elemen hingga atau (Finite Element Method) merupakan metode analisa sebuah struktur dengan mendikritisasi sebuah benda kerja sehingga menjadi elemen dengan jumlah terbatas (Finite), penggunaan metode elemen hingga banyak dilakukan untuk menganalisa struktur dikarenakan lebih mudah dalam pengoperasian dan dirasa lebih akurat untuk pemaparan hasil dari analisa.

Tujuan dari penelitian ini adalah mengetahui fatigue life, dan fatigue safety facator dari rangka sepeda trandem sehingga diharapkan penelitian ini dapat menjadi masukan serta referensi untuk pengembangan sepeda Trandem kedepannya

Dan batasan dari penelitian ini diantaranya, analisa dan permodelan difokuskan pada bagian rangka sepeda Trandem, pengelasan dianggap baik dan uniform, pembebanan hanya berasal dari pengemudi dan beban dari sepeda sendiri, pembebanan yang terjadi pada sepeda hanya pembebanan statis, dan tidak ada cacat yang terjadi pada rangka sepeda Trandem.

\section{METODOLOGI PENELITIAN}

\section{A. Prosedur Penelitian}

Pada Gambar 1, secara garis besar penelitian ini dibagi menjadi beberapa tahapan diantaranya studi literatur dan pengambilan data yang nantinya data tersebut digunakan baik dalam pembuatan geometri dengan menggunakan perangkat lunak untuk menggambar teknik ataupun perangkat lunak elemen hingga untuk dilakukan simulasi statis, dan dilanjutkan dengan simulasi fatigue sesuai standard dan pembebanan operasional, dalam penelitian ini digunakan TBIS 4210-6:2018[3] lalu dilakukan validasi terhadap hasil simulasi dengan perhitungan manual, apabila hasil simulasi menyatakan adanya overdesign pada rangka sepeda maka diberikan improvement terhadap rangka sepeda dan dilakukan simulasi kembali agar dapat diketahui efek improvement dari rangka sepeda Trandem.

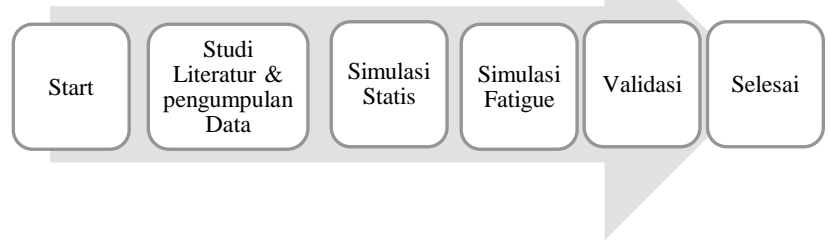

Gambar 1. Prosedur Penelitian Secara Garis Besar. 


\section{B. Studi Literatur}

Studi Literatur dilakukan dengan mecari referensi terkait dengan penelitian ini, dari mulai buku, tugas akhir sebelumnya, jurnal, website, dan lain sebagainya. Beberapa refensi yang digunakan antara lain "Analisis Fatigue pada Slewing Tower Level Luffing Cane Berbasis Metode Elemen Hingga" [4] yang dijadikan penulis sebagai dasaran dalam melakukan fatigue analysis pada penelitian ini, kemudian Thesis yang berjudul "Fatigue Behaviour of 6061 Aluminium Alloy and Its Composite" [5] yang berisikan data fatigue dari Al 6061 yang mana merupakan material yang digunakan pada penelitian kali ini, lalu yang berikutnya adalah "Analisa Tegangan dan Deformed Shape pada Rangka Sepeda Fixie”[6] yang dijadikan penulis sebagai salah satu dasaran penentuan beban pada kondisi tertentu.

\section{Pengambilan Data}

Pengambilan data dilakukan melalui beberapa sumber, diantaranya untuk data geometri sepeda Trandem didapatkan dari tim sepeda Trandem dengan geometri seperti pada Gambar 2, dengan material Al 6061 [7] dimana data material akan dijelaskan pada Tabel 1. Untuk sifat mekanik, dan Tabel 2. Untuk data fatigue dari material tersebut.

Tabel 1.

Data Fatigue dari Material Al 6061 [5]

\begin{tabular}{cc}
\hline \hline Cycle $(\mathrm{N})$ & Stress Amplitude $(\mathrm{MPa})$ \\
\hline $4.2 \times 10^{3}$ & 373.62 \\
$6.5 \times 10^{3}$ & 348.35 \\
$2 \times 10^{4}$ & 300 \\
$9 \times 10^{4}$ & 254.94 \\
$2.5 \times 10^{5}$ & 200 \\
$5 \times 10^{5}$ & 170.33 \\
$4.5 \times 10^{6}$ & 142.19 \\
$4.1 \times 10^{7}-$ did not fail & 121.97 \\
\hline \hline
\end{tabular}

Tabel 2

\begin{tabular}{cc}
\multicolumn{2}{c}{ Mechanical Properties dari Al 6061 [8] } \\
\hline \hline Properties & Unit (SI) \\
\hline Ultimate Tensile Strength & $310 \mathrm{MPa}$ \\
Tensile Yield Strength & $276 \mathrm{MPa}$ \\
Modulus of Elasticity & $68.9 \mathrm{GPa}$ \\
Poisson's Ratio & 0.33 \\
Fatigue Strength & $96.5 \mathrm{MPa}$ \\
Shear Modulus & $26 \mathrm{GPa}$ \\
Shear Strength & $207 \mathrm{MPa}$ \\
Density & $2.7 \mathrm{~g} / \mathrm{cc}$ \\
\hline \hline
\end{tabular}

\section{Proses Simulasi}

Proses simulasi dilakukan dengan menggunakan perangkat lunak elemen hingga, sebelum disimulasikan dengan perangkat lunak elemen hingga dilakukan pembuatan geometri rangka sepeda trandem seperti Gambar 2, yang nantinya dengan perangkat lunak elemen hingga dilakukan proses diskritisasi (meshing) yaitu pembagian geometri menjadi elemen elemen kecil dengan jumlah terbatas (finite), proses penentuan bentuk dan ukuran meshing dilakukan dengan melakukan uji konvergensi .

Jumlah dan ukuran elemen yang digunakan dalam penelitian kali ini akan ditentukan dengan melakukan uji konvergensi. Bentuk meshing yang diterapkan pada geometri rangka sepeda trandem adalah Automatic Mesh dikarenakan sulit untuk mendapatkan kualitas meshing maksimum ketika diterapkan Hex Dominant. Dilakukan uji konvergensi dengan mengubah Span Angle dan ukuran meshing pada Element Size. Hasil simulasi berupa Maximum Stress dari setiap variasi akan dibandingkan dan dilakukan perhitungan error, apabila element quality sudah baik dan error dari simulasi sudah mencapai $\leq$ 5\% maka meshing dapat dikatakan konvergen.

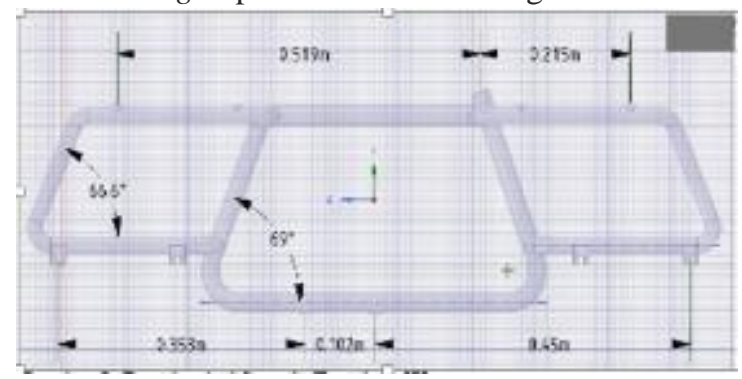

Gambar 2. Rangka dari Sepeda Trandem [7].

Uji konvergensi dilakukan dengan mengubah span angle dari coarse, medium, dan fine, dengan variasi ukuran meshing dari deffault, $10 \mathrm{~mm}, 9 \mathrm{~mm}, 8 \mathrm{~mm}, 7 \mathrm{~mm}, 6 \mathrm{~mm}, 5 \mathrm{~mm}$, dan $4 \mathrm{~mm}$.

Didapat nilai mehsing dengan error terendah berada pada ukuran $5 \mathrm{~mm}$ pada span angle coarse, medium, dan fine, dengan kualitas meshing sebesar 68\%, 69\% dan 70\%. Berdasarkan hasil tersebut, ukuran meshing sebesar $5 \mathrm{~mm}$ dengan span angle fine dipilih untuk penelitian kali ini.

\section{E. Simulasi Sesuai Standard Taiwan Bicycle Industrial Standard (TBIS 4210-6:2018) [3]}

Pengujian fatigue mengacu kepada TBIS 4210-6:2018 terdiri dari 2 pengujian, yaitu pengujian terhadap horizontal force, dan pedaling force. Simulasi fatigue terhadap horizontal force dilakukan sesuai dengan Gambar 3., dengan kondisi pembebanan dilakukan seperti Gambar 4. Karena sepeda Trandem diperuntukan untuk penggunaan masyarakat perkotaan, oleh karena itu dipilih kasus city and trekking bicycles untuk pengujian fatigue pada kasus ini.

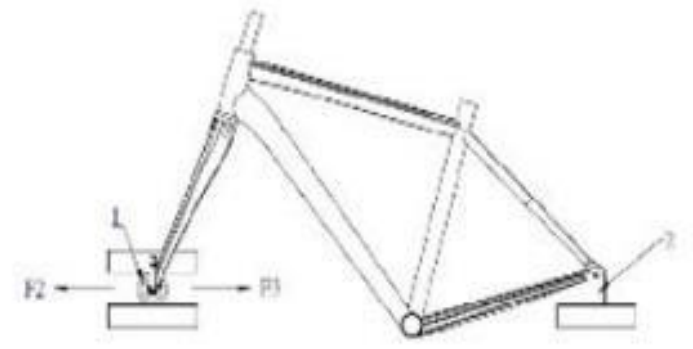

Gambar 3. Skema Pembebanan Terhadap Horizontal Force.

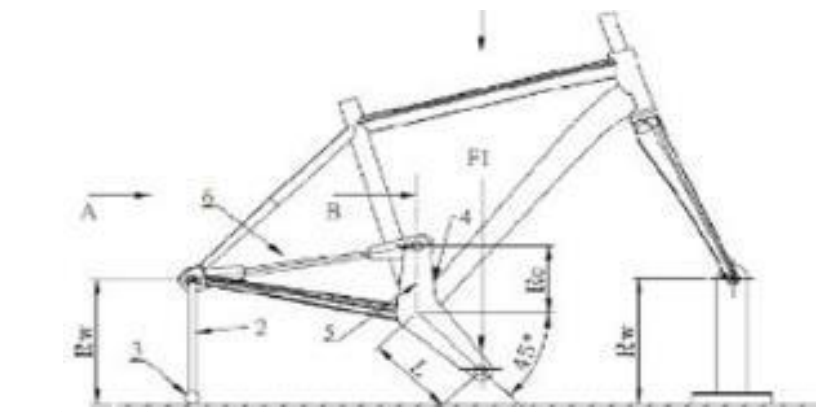

Gambar 4. Skema Pembebanan Terhadap Pedaling Force. 
Dilakukan 2 tahap pengujian pada pengujian ini yaitu stage 1 dan stage 2, dimana pada stage 1 frame sepeda diharuskan untuk melewati 120000 cycle dengan gaya $\mathrm{F}_{2}$ dan $\mathrm{F}_{3}$ sebesar $450 \mathrm{~N}$, dan pada stage 2 sebanyak 100000 cycle dengan besar $\mathrm{F}_{2}$ dan $\mathrm{F}_{3}$ sebesar $500 \mathrm{~N}$. Apabila sepeda dapat melalui test cycle tersebut maka sepeda dapat dikatakan aman. Simulasi dilakukan dengan Load Condition yang mengacu kepaada TBIS 4210-6:2018

Untuk pengujian pedaling force dilakukan mengacu kepada TBIS 4210-6:2018 dengan kondisi seperti pada Gambar 4. dengan nilai $F_{1}$ sebesar $1000 \mathrm{~N}$ untuk Stage 1 dan $1100 \mathrm{~N}$ untuk stage 2. Rangka Sepeda dapat dikatakan aman apabila dapat melaui 120.000 cycle untuk stage 1, dan 100.000 cycle untuk pengujian stage 2 .

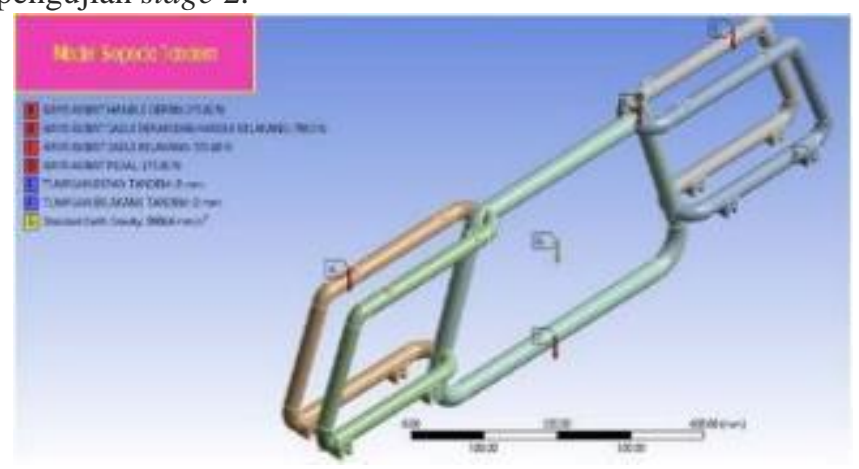

Gambar 5. Kondisi Pembebanan pada Rangka Sepeda Trandem.

\section{F. Simulasi dengan Pembebanan Operasional}

Pada simulasi ini pembebanan akan berasal dari beban operasional yang berasal dari 2 pengendara dengan massa 100 kg yang berlokasi pada bagian sadle, handle, dan pedal dari sepeda seperti pada Gambar 5, dengan pembagian pembebanan $22 \%$ dari beban pengemudi berada pada handle, dan pedal, dan sebesar 55\% berada pada sadle [5] yang ditabulasi seperti pada Tabel 3. sebagai pembebanan dalam kondisi minimum. Beban maksimum didapat dari hasil perhitungan beban operasional pengemudi dengan memperhitungkan kondisi jalan yang yaitu pada kondisi kritis dimana pengendara menghadapi road bump dengan tinggi $\pm 20 \mathrm{~cm}$, dan diberikan Dynamic Factor sebesar 3 , sehingga gaya yang bekerja saat kondisi ini adalah 3 kali dari beban operasional [9] dengan kondisi pembebanan seperti pada Gambar 5. dengan besar pembebanan seperti pada Tabel 3.

Tabel 3.

Besar dan Lokasi Pembebanan Operasional

\begin{tabular}{lcc}
\hline \multirow{2}{*}{ Lokasi Pembebanan } & \multicolumn{2}{c}{ Besar (N) } \\
\cline { 2 - 3 } & Minimum & Maksimum \\
\hline Handle & 215.82 & 647.46 \\
Sadle Depan + Handle Belakang & 755.37 & 2266.11 \\
Sadle Belakang & 539.55 & 1618.65 \\
Pedal & 215.82 & 647.46 \\
Beban Sepeda & 20.9361 & 20.9361 \\
\hline \hline
\end{tabular}

\section{G. Simulasi Fatigue}

Simulasi fatigue dilakukan dengan menentukan jenis pembebanan pada tiap pengujian, untuk pengujian sesuai TBIS 4210-6:2018 pembebanan dilakukan secara fully reversed dengan scale factor sebesar -1 dengan Mean Stress Theory yang digunakan yaitu Gerber, lalu untuk simulasi fatigue akibat dari pembebanan operasional, terlebih dahulu dicari besarnya tegangan maksimum akibat dari pembebanan minimum $(\sigma \mathrm{min})$ dan maksimum ( $\sigma$ max), yang mana nilai tersebut digunakan sebagai dasaran perhitungan rasio tegangan siklik $(R)$ dengan Persamaan (1).

$$
R=\frac{\sigma \min }{\sigma \max }
$$

Setelah didapatkan nilai dari rasio tegangan siklik $(R)$ apabila nilai $\mathrm{R}=-1$ maka digunakan kondisi pembebanan fully reversed, dan apabila nilai $\mathrm{R}=0$ atau $\mathrm{R}=\infty$ berarti kondisi pembebanannya adalah zero based, dan apabila nilai $R$ bukan $0, \infty$, atau -1 maka pembebanan yang terjadi adalah pembebanan siklik dengan rasio teganan siklik dari hasil perhitungan persamaan (1), dengan Mean Stress Theory yaitu Gerber.

Persamaan Gerber dapat dilihat dari persamaan (2) adalah persamaan digunakan untuk mencari nilai dari Alternating Stress pada penelitian ini, yang nantinya nilai Alternating Stress akan digunakan dalam perhitungan untuk mencari nilai dari fatigue life.

$$
\text { Alternating Stress }=\sigma_{a}\left(\frac{s_{u}^{2}}{S_{u}^{2}-\sigma_{m}^{2}}\right)
$$

\section{H. Tahap Validasi}

Tahap validasi dilakukan pada tiap tahapan simulasi dengan tujuan untuk mengetahui apakah simulasi sudah berjalan sesuai dengan teori atau belum. Validasi pada simulasi fatigue dilakukan validasi dengan membandingkan hasil simulasi dengan hasil perhitungan manual yaitu perhitungan dengan menggunakan persamaan dari grafik $S$-N Curve Al 606, Gambar 6 yang didapatkan dari hasil plotting data fatigue Al $6061 \mathrm{ke}$ dalam bentuk grafik melalui perangkat lunak spreadsheet, sehingga dapat diketahui trendline dari grafik sehingga hubungan antara Alternating Stress $(\mathrm{S})$ dan Cycle $(\mathrm{N})$ dari $A l$ 6061 dapat diketahui ke dalam bentuk persamaan (3).

$$
S=1096,2 \times N^{0,312}
$$

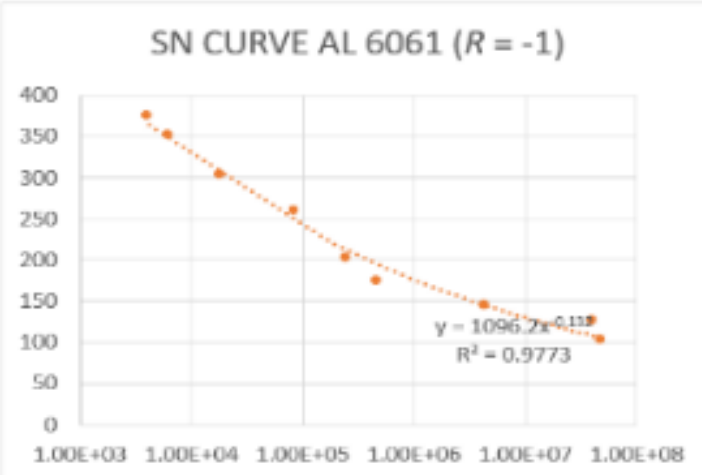

Gambar 6. Grafik dari S-N Curve dari Al 6061 dalam Bentuk Semi-log.

Hasil cycle yang didapat nantinya akan dikonversi menjadi tahun dengan asumsi sepeda digunakan dengan kecepatan 20 $\mathrm{km} / \mathrm{jam}$ dan beroperasi selama 24 jam sehari maka, dalam satu hari sepeda menempuh jarak sejauh $480 \mathrm{~km}$ dengan asumsi kedua yaitu dalam $1 \mathrm{~km}$ terjadi satu siklus beban siklik akibat irregularity pada jalan sehingga didapat 480 cycle dalam 1 hari. Sehingga Fatigue Life dari rangka sepeda dapat dikonversi menjadi tahun seperti perhitungan berikut:

1. Cycle per hari $=480 \mathrm{cycle} / \mathrm{hari}$ 
2. Dalam satu tahun $=365$ hari/tahun $\mathrm{x} 480 \mathrm{cycle} / \mathrm{hari}$ $=175.200$ cycle/tahun

Apabila hasil dari perbandingan perhitungan manual denan hasil simulasi didapatkan error yang kecil maka dapat dikatakan bahwa simulasi fatigue yang dilakukan sudah sesuai dengan kenyataan aktualnya.

\section{DATA HASIL PENELITIAN DAN PEMBAHASAN}

\section{A. Hasil Simulasi dengan Kondisi Pembebanan sesuai TBIS 4210-6:2018}

Didapat hasil Didapat Maximum Stress 29.06 MPa untuk pembebanan horizontal force pada Gambar 7, dan sebesar 112.21 MPa pada Gambar 8 untuk pembebanan pedaling force, dari hasil tersebut dapat dikatakan bahwa rangka ini aman dari segi statis dikarenakan masih jauh dibawah Ultimate Strength dari material Al 6061 T6, dan didapatkan maxium Stress berada pada lokasi sambungan yang sesuai dengan kondisi aktual dari pengujian fatigue pada rangka sepeda menurut TBIS 42106:2018, karena salah satu tujuan dari pengujian fatigue adalah untuk mengetahui kekuatan sambungan dari frame sepeda yang diujikan.

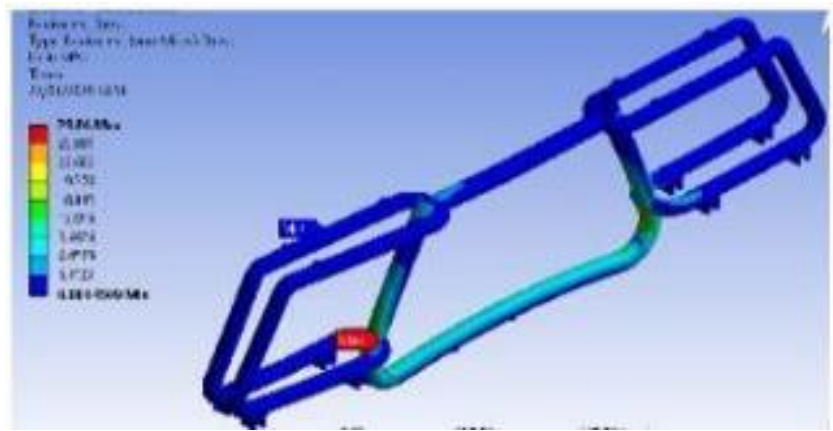

Gambar 7. Tegangan Maksimum Hasil Simulasi Fatigue Terhadap Horizontal Force.

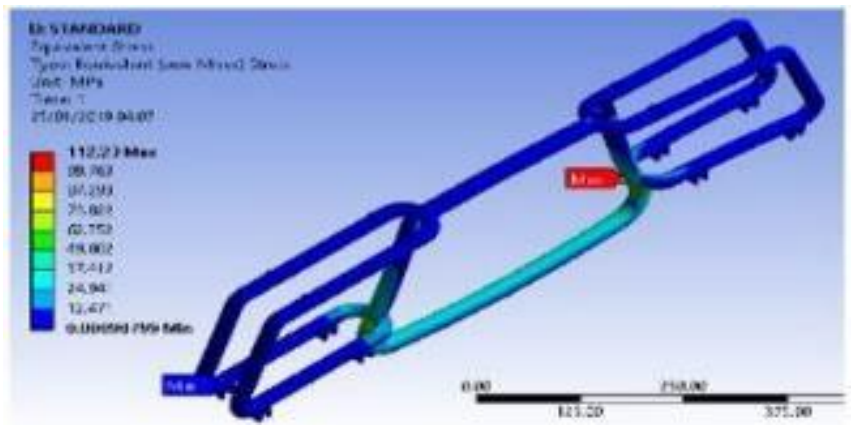

Gambar 8. Tegangan Maksimum Hasil Simulasi Fatigue Terhadap Pedaling Force.

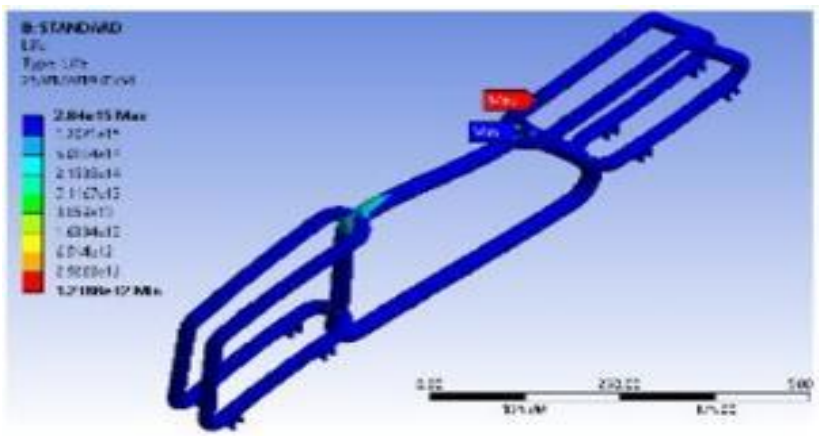

Gambar 9. Hasil Fatigue Life dari Simulasi Terhadap Horizontal Force.

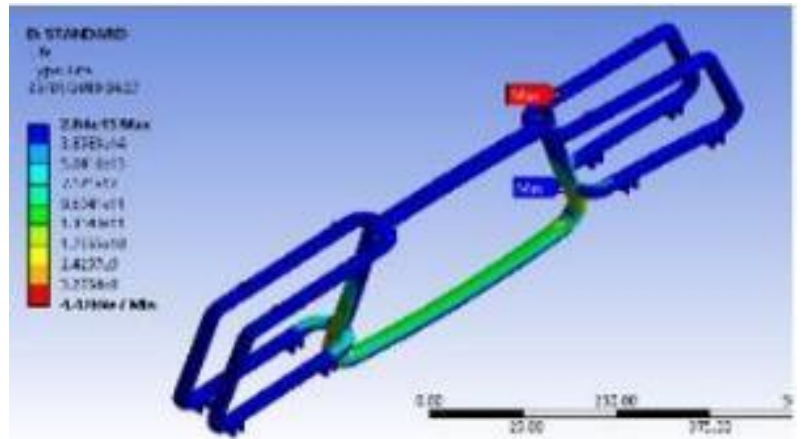

Gambar 10. Hasil Fatigue Life dari Simulasi Terhadap Pedaling Force.

Didapatkan bahwa Fatigue Life dari sepeda trandem mencapai 2.84e15 cycle pada Gambar 9 dan Fatigue Life terendah yang dapat dicapai pada pengujian ini adalah sebesar $1.24 \mathrm{e} 12$ cycle pada Gambar 10 yang berlokasi pada sambungan las pada rangka sepeda, hal ini sejalan dengan besaran tegangan yang terjadi, dimana lokasi dengan tegangan terbesar memiliki nilai Fatigue Life yang terendah, begitu pula sebaliknya, yang mana rangka sepeda dapat dikatakan aman karena menurut TBIS 4210-6:2018 rangka harus melewati 120.000 cycle agar dapat dikatakan aman.

\section{B. Hasil dari Simulasi dengan Beban Operasional}

Dari data hasil simulasi didapat tegangan maksimum dari hasil pembebanan operasional minimum adalah sebesar 70.263 Mpa pada Gambar 11, dan tegangan maksimum hasil dari pemebanan operasional maksimum adalah sebesar $210.2 \mathrm{Mpa}$, Gambar 12. Lokasi terjadinya tegangan maksimum juga sama dengan hasil hasil sebelumnya, dimana lokasi sambungan merupakan titik dimana terjadinya tegangan maksimum. Hasil diatas nantinya akan digunakan untuk mendapatkan nilai rasio tegangan siklik (R) melalui persamaan (1) dan didapatkan hasil rasio tegangan siklik sebesar 0.334278 yang menandakan bahwa pembebanan siklik yang terjadi tidak berasal dari pembebanan fully reversed atau zero based melainkan pembebanan siklik dengan rasio dari hasil persamaan (1).

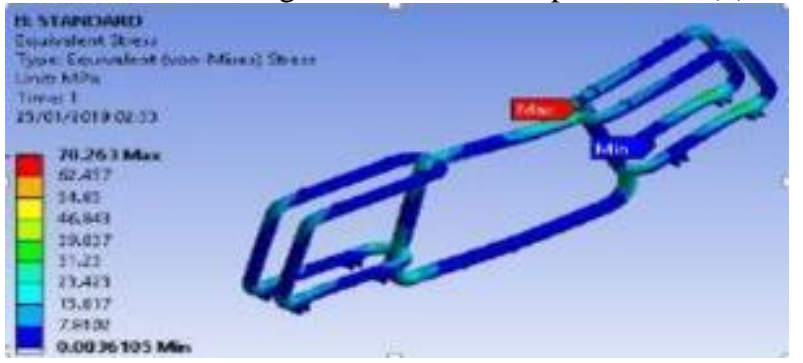

Gambar 11. Hasil Tegangan Maksimum dari Kondisi Pembebanan Operasional Minimum.

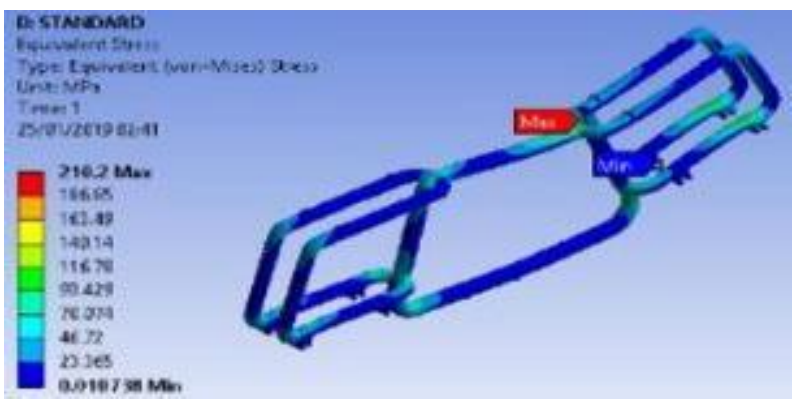

Gambar 12. Hasil Tegangan Maksimum dari Kondisi Pembebanan Operasional Maksimum. 


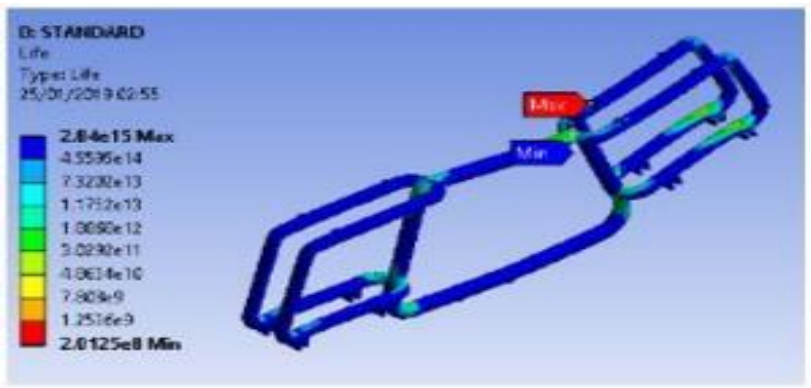

Gambar 13. Fatigue Life Hasil dari Pembebanan Operasional.

Pada Gambar 13, nilai rasio tegangan siklik nantinya akan digunakan untuk melakukan simulasi fatigue dan didapatkan hasil fatigue life sebesar $2.84 \mathrm{e} 15$ cycle maksimum, dan $2.0125 \mathrm{e} 8$ cycle minimum dimana dengan nilai fatigue safety factor sebesar 0.8626 - 15 dimana nilai 15 adalah safety factor maksimum yang dapat ditunjukan oleh perangkat lunak elemen hingga yang digunakan dalam penelitian ini.

\section{Perbandingan Hasil Simulasi dengan Perhitungan}

Dilakukan perhitungan secara manual untuk melakukan validasi terhadap simulasi yang dilakukan. Pada simulasi fatigue dilakukan perhitungan manual untuk mengetahui nilai alternating stress dengan persamaan (2) yang dilanjutkan dengan mencari nilai cycle dari nilai alternating stress yang didapat dengan menggunakan persamaan (3) dilanjutkan dengan konversi fatigue life dari satuan cycle menjadi tahun dengan konversi yang sudah dibahas pada bagian sebelumnya. Dari hasil diatas didapatkan bahwa antara perhitungan manual dengan hasil simulasi memiliki selisih yang sedikit, sehingga dapat dikatakan bahwa simulasi sudah sesuai dengan teori yang ada. Hasil simulasi juga mengindikasikan adanya overdesign dari rangka sepeda dikarenakan fatigue life dari sepeda dirasa terlalu lama, oleh karena itu dimungkinkan dilakukan improvement terhadap sepeda agar tidak terjadi overdesign.

Tabel 4.

Perbandingan Hasil Perhitungan Manual dengan Hasil Simulasi

\begin{tabular}{ccc}
\hline \hline & Perhitungan Tangan & Hasil Simulasi \\
\hline $\begin{array}{c}\text { TBIS Horizontal } \\
\text { Force }\end{array}$ & 6.59e6 Tahun & 7.19e6 Tahun \\
$\begin{array}{c}\text { TBIS Pedaling } \\
\text { Force }\end{array}$ & 183 Tahun & 19.2 Tahun \\
$\begin{array}{c}\text { Pembebanan } \\
\text { Operasional }\end{array}$ & 2.96e6 Tahun & 2.51e6 Tahun \\
\hline \hline
\end{tabular}

\section{Improvement}

Dari hasil pengujian sebelumnya, desain dari rangka sepeda Trandem ini mengalami overdesign, dikarenakan hasil dari fatigue life dirasa terlalu berlebih hingga mencapai ratusan tahun setelah dikonversikan kedalam tahun, sehingga dilakukan improvement terhadap desain dari rangka sepeda Trandem.

Terdapat banyak pilihan untuk melakukan improvement seperti melakukan pergantian material, atau pergantian bentuk dari geometri sepeda Trandem. Pergantian material terhadap desain ini dirasa belum dibutuhkan karena pemilihan material sudah dilakukan pada penelitian sebelumnya, dan didapat material Al 6061 sebagai material optimum, sehingga pilihan improvement dapat dilakukan dengan pergantian dimensi atau geometri dari rangka sepeda Trandem.
Perubahan geometri dari rangka sepeda Trandem urung dilakukan karena melihat nilai fungsional dari rangka sepeda Trandem berada pada bentuk geometri dari rangka sepeda Trandem itu sendiri, dan akhirnya dilakukan improvement berupa perubahan dimensi dari ketebalan rangka sepeda Trandem yang semula setebal $0.3 \mathrm{~mm}$ menjadi $0.15 \mathrm{~mm}$.

Efek dari improvement tersebut didapatkan perubahan yang cukup jauh. Didapatkan fatigue life dari hasil improvement adalah sebesar $1.053 \mathrm{e} 11$ cycle dan $2.95 \mathrm{e} 6$ cycle untuk simulasi pada horizontal force dan pedaling force pada TBIS 42106:2018 pada Gambar 14 dan Gambar 15, dan faitgue life hasil dari pembebanan operasional adalah sebesar $3.048 \mathrm{e} 6$ cycle pada Gambar 16, dan tabulasi dari hasil simulasi dituangkan dalam Tabel 5.

Tabel 5.

Hasil Simulasi Setelah Improvement

\begin{tabular}{ccc}
\hline \hline & Design & Hasil \\
& Sebelumnya & Improvement \\
\hline TBIS Horizontal Force & 7.19e6 Tahun & 6.1e5 Tahun \\
TBIS Pedaling Force & 251 Tahun & 17.2 Tahun \\
Pembebanan Operasional & 1.51e6 Tahun & $\mathbf{1 7 . 6}$ Tahun
\end{tabular}

Fatigue life hasil improvemennt turun hingga menyentuh angka 18 tahun dengan fatigue safety factor sebesar 1.0194 15 yang mana hasil ini dirasa cukup, karena pada rangka sepeda dapat melalui pengujian fatigue dengan standar TBIS 42106:2018, dan pada simulasi fatigue oleh pembebanan operasional, sepeda dapat menahan beban 3 kali dari beban operasionalnya, sehingga rangka sepeda Trandem dirasa cukup aman setelah dilakukan improvement.

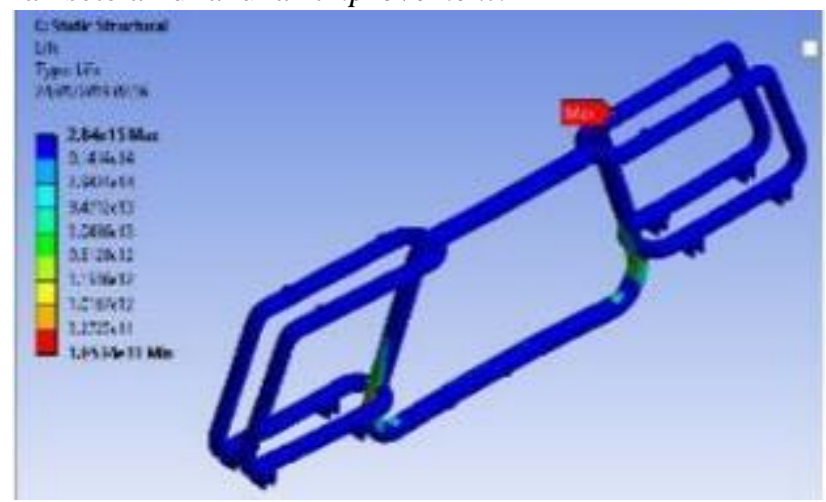

Gambar 14. Hasil Fatigue Life dari Rangka Hasil Improvement dengan Pembebanan dari Horizontal Force.

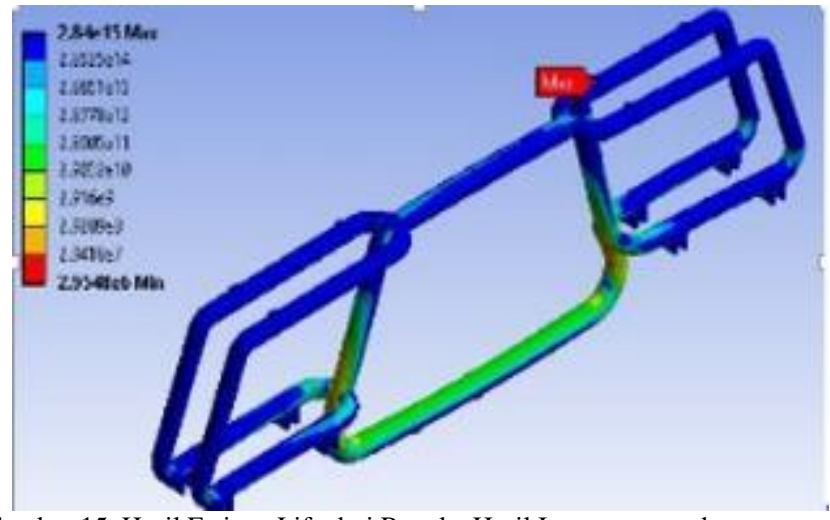

Gambar 15. Hasil Fatigue Life dari Rangka Hasil Improvement dengan Pembebanan dari Pedaling Force. 


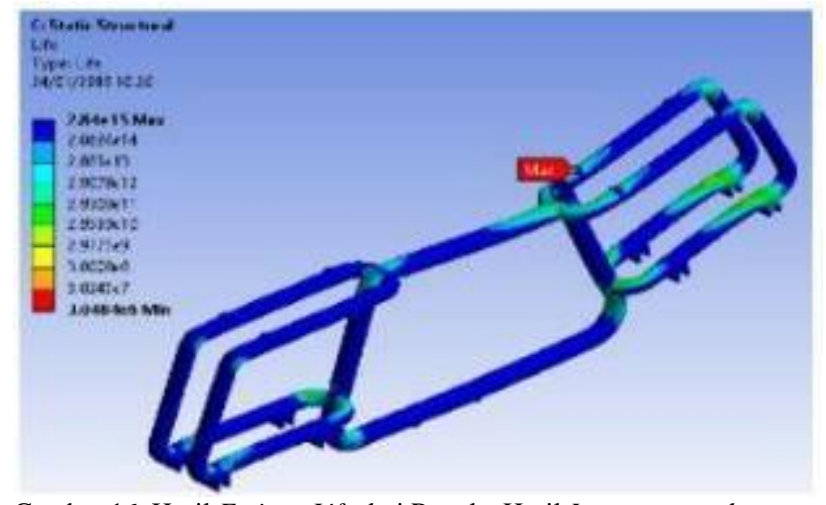

Gambar 16. Hasil Fatigue Life dari Rangka Hasil Improvement dengan Pembebanan Operasional.

\section{KESIMPULAN \& SARAN}

\section{A. Kesimpulan}

Berdasarkan simulasi yang sudah dilakukan terhadap rangka sepeda Trandem, didapatkan kesimpulan sebagai berikut :

1. Fatigue Life dari Sepeda Trandem berada pada nilai $1.15 \mathrm{e}+3$ tahun berdasarkan perhitungan manual, dan hal ini sejalan dengan hasil simulasi yang menyatakan bahwa Fatigue Life dari sepeda trandem berada pada nilai $1.17 \mathrm{e}+3$ tahun

2. Fatigue Safety Factor dari Sepeda Trandem berada pada rentang 0.8626 hingga 15 (Maksimum)

3. Terindikasi adanya overdesign dari sepeda dikarenakan hasil dari fatigue life mencapai angka hingga ratusan tahun, yang mana dirasa berlebihan, oleh karena itu dibutuhkan improvement terhadap geometri atau material dari rangka sepeda Trandem

4. Dilakukan improvement dengan merubah ketebalan rangka sepeda dari yang semula $3 \mathrm{~mm}$ menjadi $1.5 \mathrm{~mm}$, dan didapatkan perubahan yang cukup besar, yang semula umur fatigue dari sepeda mencapai angka $1.17 \mathrm{e} 3$ tahun, umur fatigue dari rangka sepeda Trandem dapat turun mencapai 18 tahun dengan fatigue safety factor 1.09-15

\section{B. Saran}

Berdasarkan hasil, dan kendala selama proses simulasi ini maka penulis memberikan saran sebagai berikut :

1. Permodelan geometri bisa didetailkan lagi hingga terdefinisi bentuk dari fork dan sambungan yang aktual dengan geometri sesungguhnya

2. Pada proses simulasi didapatkan tegangan tertinggi pada bagian sambungan antara lokasi sadle dengan rangka sepeda, yang mungkin dapat diatasi dengan penambahan ketebalan, atau pergantian material

3. Dapat digunakan Reversed Bending $S-N$ Curve untuk dilakukan dalam penelitian, karena diindikasi kegagalan dapat terjadi akibat bending, dan juga tensile/compression

\section{DAFTAR PUSTAKA}

[1] "Bicycle Production Reaches 130 Million Units | Worldwatch Institute.".

[2] "EPI Releases - Bicycle Share Fact Sheet | EPI.".

[3] Taiwan, Taiwan Bicycle Standard 2018. Taiwan, 2018.

[4] H. A. R. Cahyono, J. B. Ariatedja, and J. B. Ariatedja, "Analisis Fatigue pada Slewing Tower Level Luffing Crane Berbasis Metode Elemen Hingga," J. Tek. ITS, vol. 7, no. 2, pp. B128-B133, Dec. 2018.

[5] P. H. Lim and L. Looney, "Fatigue Behaviour of 6061 Aluminium Alloy and Its Composite M aster in Engineering," 2001.

[6] A. Berlianto, "Analisa Struktur Rangka Sepeda Fixie dengan Menggunakan Metode Elemen Hingga."

[7] B. Iskandriawan, A. Windharto, and A. Dwi Krisbianto, "Main Frame Structure Exploration of Sliding Tandem Bike as the Effort to Enhance Product Feature."

[8] "Mechanical Propertiers of Al 6061 T6.".

[9] J. Brown and A. Robertson, "Motor Vehicle Structures: Concepts and Fundamentals." 